\section{OPTIMIZATION OF THE CONCRETE DELIVERY AND PLACEMENT PROCESS USING A SIMULATION}

\begin{abstract}
Integrated construction processes are stochastic systems. For these cases a computer simulation is used. This paper presents the design and construction of an integrated construction process, i.e., the production-transportation-consumption of fresh concrete. When creating a model in an Extend v4, modelling techniques and a general knowledge of construction are used. Data obtained from actual processes is used for the model parameters and input variables. The main contribution is a simulation model developed for the process for the optimization and selection of variants. This approach complements the heuristic methods of the assessment of construction processes and exact methods, where the decisive body will have the values of the individual decision-making criteria.
\end{abstract}

Juraj TALIAN
Email: talian@atlas.sk
Research field: Construction technology,
fresh concrete, simulation, concrete
transportation, construction.
Address: Department of Construction
Technology, Faculty of Civil Engineering
Slovak University of Technology
in Bratislava
Radlinského 11, 813 Bratislava,
Slovak Republic

\section{KEY WORDS}

- Integrated construction process,

- computer simulation,

- fresh concrete.

\section{INTRODUCTION}

"Construction $=$ Transport." Such a catchword can describe construction, which is the hallmark of processing large amounts of materials which are associated with significant requirements for transportation.

Concrete operations can be described as including several processes such as batching, transport and placement, and are common to many construction sites. Simulation techniques can be applied to the modelling of the delivery and placement process of concrete in order to study different combinations of resources (Smith, 1998; 1999).

This paper will look at a concreting system that, in its simplest form, consists of batching, transport and finally placement. The simulation techniques can be applied to the modelling of this integrated construction process in order to study different combinations of resources and optimization. The simulation tool Extend can be used to simulate this process (Dunlop 2003). It is a simple and powerful tool as demonstrated by many researchers.

\section{DESCRIPTION OF THE PROBLEM}

The "transportation - consumption" system of fresh concrete (FC) is part of the integrated construction process "production - transportation - consumption" of fresh concrete (P-T-C FC). Transportation is a necessary and important interface of two technologies: technologies of production and processing technologies of FC. The (P-T-C) system is a system with a target behaviour, where the ultimate goal is output from the "consumption" (C) subsystem. From the output of subsystem (C) the loading and processing of fresh concrete is implemented. The success rate of the implementation is dependent on the quality of the transformation in (C), but also on the intensity and quality of the $(\mathrm{P})$ and $(\mathrm{T})$ output subsystems, which form the input trajectory of subsystem $(\mathrm{C})$.

Subsystem $(\mathrm{P})$ has within the P-T-C FC system a special position. Its capacity is proposed to simultaneously serve more than one system (T-C). Based on a complex internal structure, subsystem (P) creates a special set of issues similar to those incurred in producing construction materials. These are not the subject of this paper, and subsystem $(\mathrm{P})$ is taken only as a source of fresh concrete.

In the (T-C) system the impact of subsystem (S) is directly reflected and has a relatively independent position with regard to $(\mathrm{P}-\mathrm{T}-\mathrm{C})$. To ensure the proper functioning of the internal functions of the (P-T-C) system, it is important for all of its components and subsystems to be proportionally matched. To preserve the internal rhythm of (T-C), execution of the following condition is required: 


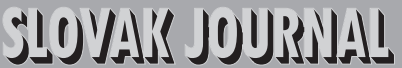 \\ 1) $)^{5}$

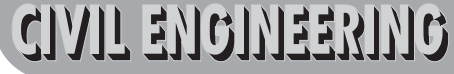

Vol. XXI, 2013, No. 2, 1 - 6

$$
\mathrm{C}_{\mathrm{T}}=\mathrm{C}_{\mathrm{C}}
$$

where

$$
\begin{array}{lll}
\mathrm{C}_{\mathrm{T}} & - \text { transportation capacity } & {\left[\mathrm{m}^{3} / \mathrm{h}\right]} \\
\mathrm{C}_{\mathrm{C}}-\text { consumption capacityn } & {\left[\mathrm{m}^{3} / \mathrm{h}\right]}
\end{array}
$$

Common practice shows that condition (1) cannot be met in a number of ways. If $\mathrm{C}_{\mathrm{T}}>\mathrm{C}_{\mathrm{C}}$, then the environment (site) is loaded with excessive impacts due to the formation of queues in the subsystem (C). If $\mathrm{C}_{\mathrm{T}}<\mathrm{C}_{\mathrm{C}}$, then the lack of fresh concrete results in (C) loss of performance, and the (T-C) system does not meet its targeted focus on the desired intensity.

The integrated construction process (P-T-C) of fresh concrete can be characterized as closed queuing system with two channels arranged in a series. It consists of an entry and the four phases of the operation, where the output of the fourth phase is also entering the first phase is return (Fig.1).

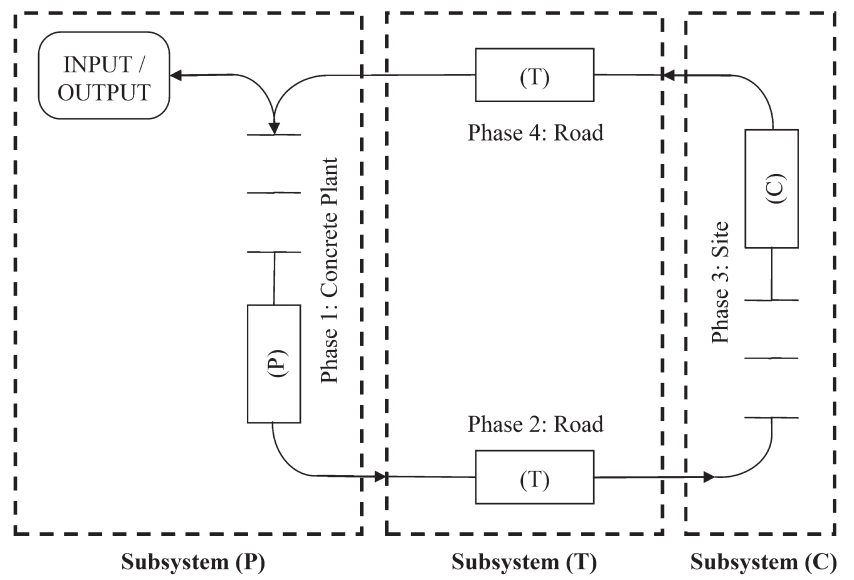

CREATION OF THE SIMULATION MODEL

Fig. 1 Scheme of the P-T-C FC integrated construction process.

\section{CREATION OF THE SIMULATION MODEL}

The basic concept is to model the transportation flow of fresh concrete from the production site $(\mathrm{P})$ to the placement site $(\mathrm{C})$. The model consist of hierarchical blocks, which arise by grouping the basic blocks into larger units, according to a logical structure and functions. The hierarchical blocks represent the static elements of the model and trucks represent the dynamic elements. The fundamental functioning of the simulation model is represented by the cyclical movements of transit mixers. These work until the required amount of fresh concrete is transferred. The simulation model consists of four hierarchical blocks (Fig. 2).

The function of the model is to transform the input parameters defined by the relationships and parameters for the output variables. The variables during the simulation are changing their values, while the model parameters remain constant.

The optimization and evaluation of the individual variants is the base time synthesis of the process, i.e., the total duration of the process, which is expressed by the following formula:

where

$$
T_{I C P}=\sum_{i=1}^{m} T C_{i}
$$

$$
\mathrm{TCi}=\mathrm{T}_{(\mathrm{P}) \mathrm{i}}+\mathrm{T}_{(\mathrm{P}-\mathrm{C}) \mathrm{i}}+\mathrm{T}_{(\mathrm{C}) \mathrm{i}}+\mathrm{T}(\mathrm{C}-\mathrm{P})_{\mathrm{i}}
$$

$$
\begin{array}{lll}
\mathrm{T}_{\mathrm{ICP}} & - \text { total duration of the process } & {[\mathrm{h}]} \\
\mathrm{TCi} & - \text { duration of the } \mathrm{i}-\text { th cycle } & {[\mathrm{h}]} \\
\mathrm{m} & {[-]} \\
\mathrm{T}_{(\mathrm{P}) \mathrm{i}}-\text { number of cycles } & \text { continuance in the subsystem }(\mathrm{P}) & {[\mathrm{h}]} \\
\mathrm{T}_{(\mathrm{P}-\mathrm{C}) \mathrm{i}}-\text { transportation duration from }(\mathrm{P}) \text { to }(\mathrm{C}) & {[\mathrm{h}]} \\
\mathrm{T}_{(\mathrm{C}) \mathrm{i}}-\text { continuance in the subsystem }(\mathrm{C}) & {[\mathrm{h}]} \\
\left.\mathrm{T}_{(\mathrm{C}-\mathrm{P})}\right)_{\mathrm{i}}-\text { transportation duration from }(\mathrm{C}) \text { to }(\mathrm{P}) & {[\mathrm{h}]}
\end{array}
$$

As a suitable simulation environment for creating a model, the Extend software has been selected. It is currently one of the leading object-oriented simulation tools and is the first tool designed for users of different disciplines, which in addition to realizing a wide range of simulations, also offers the possibility of developing their own libraries and blocks. The program is a product of "Imagine That, Inc." (Straka 2007).

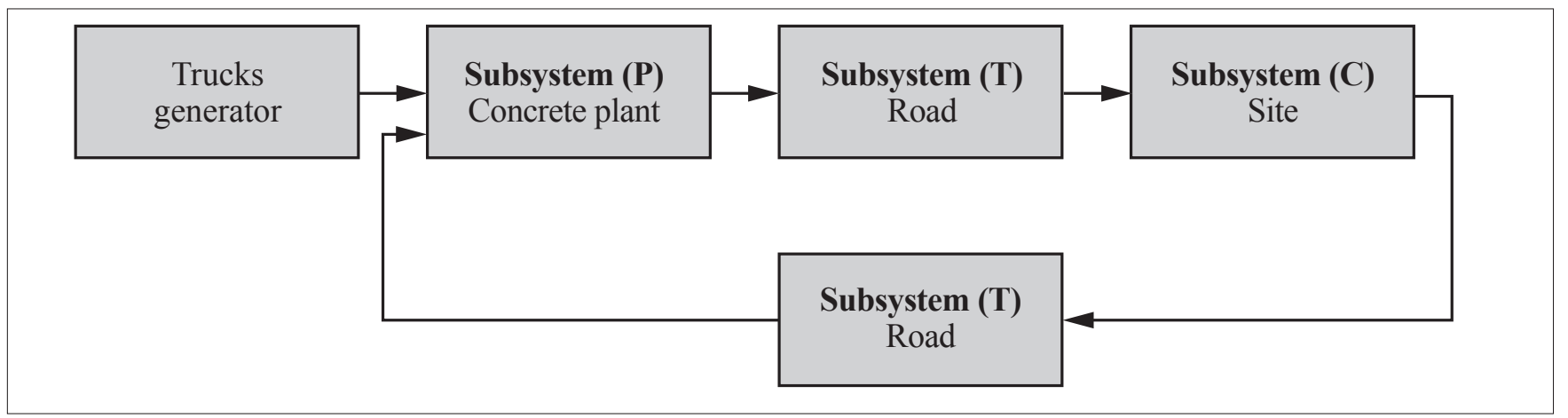

Fig. 2 Basic hierarchical blocks of the Simulation Model. 


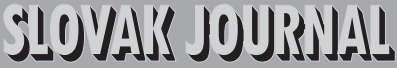

Vol. XXI, 2013, No. 2, 1 - 6

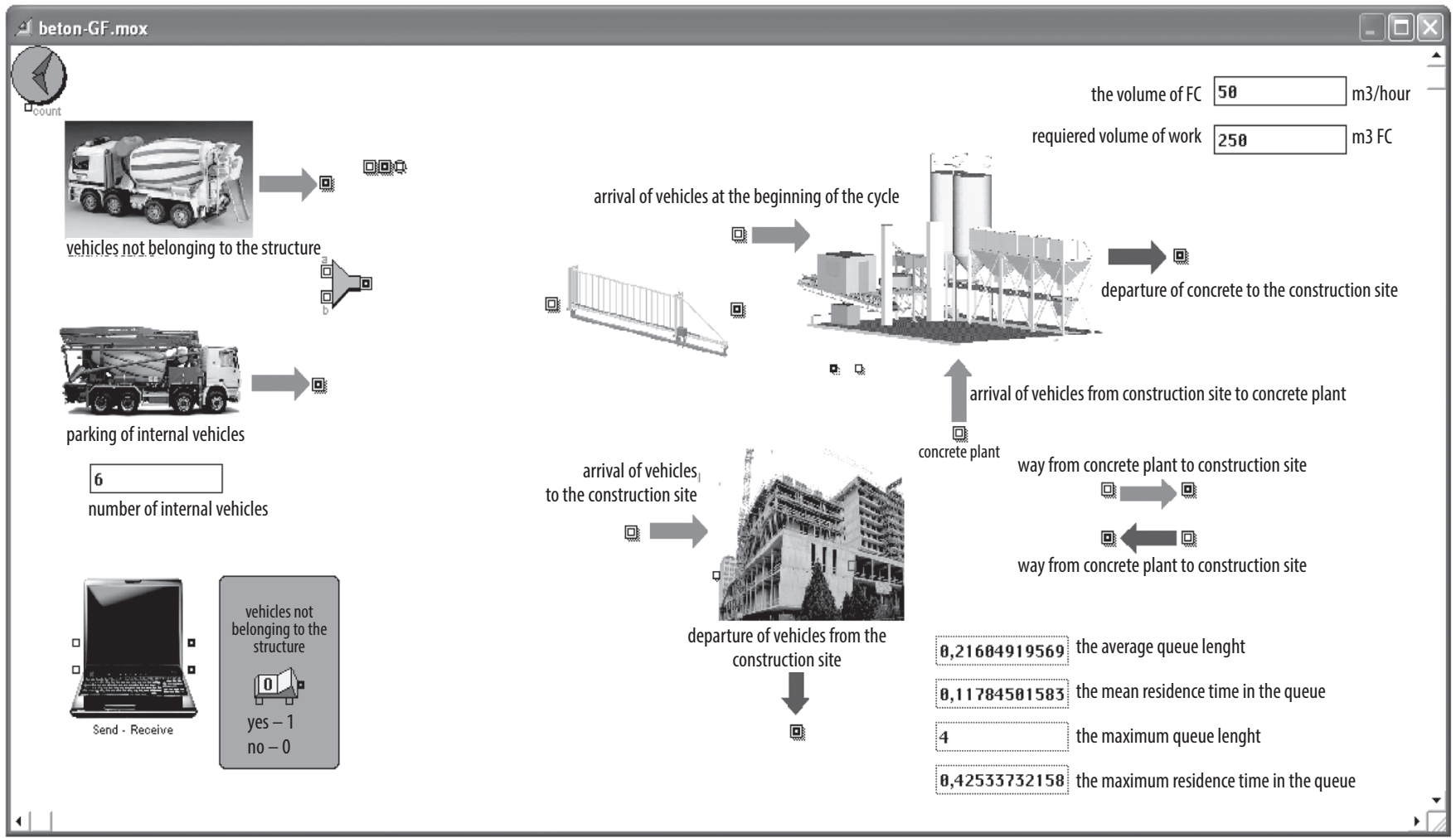

Fig. 3 Basic screen of the Simulation Model.

Data sent to or received from the simulation model are read (recorded) from / to a table created in MS Excel using the special blocks "Send" and "Receive" from the library IPC.mox, which serve to link the simulation program Extend v4 and the external spreadsheet processor.

Tab. 1 Input data of the Simulation Model.

\begin{tabular}{|c|l|c|}
\hline Subsystem & Parameter name & Sign \\
\hline \multirow{5}{*}{$(\mathbf{P})$} & Volume of the FC & $\mathrm{Q}_{\mathrm{ICP}}$ \\
\cline { 2 - 3 } & Dosage performance of FC & $\mathrm{P}_{(\mathrm{P})}$ \\
\cline { 2 - 3 } & Number of trucks & $\mathrm{PV}$ \\
\cline { 2 - 3 } & Average transportation capacity & $\mathrm{O}_{\mathrm{pr}}$ \\
\cline { 2 - 3 } & Filling duration & $\mathrm{TP}_{(\mathrm{P})}$ \\
\cline { 2 - 3 } & Manipulation duration & $\mathrm{TM}_{(\mathrm{P})}$ \\
\hline \multirow{3}{*}{$(\mathbf{T})$} & Transport duration from $(\mathrm{P})$ to $(\mathrm{C})$ & $\mathrm{TJ}_{(\mathrm{P}-\mathrm{C})}$ \\
\cline { 2 - 3 } & Transport duration from $(\mathrm{C})$ to $(\mathrm{P})$ & $\mathrm{TJ}_{(\mathrm{C}-\mathrm{P})}$ \\
\hline \multirow{3}{*}{ (C) } & Processing performance of $\mathrm{FC}$ & $\mathrm{P}_{(\mathrm{C})}$ \\
\cline { 2 - 3 } & Emptying duration & $\mathrm{TV}_{(\mathrm{C})}$ \\
\cline { 2 - 3 } & Manipulation duration & $\mathrm{TM}_{(\mathrm{C})}$ \\
\hline
\end{tabular}

Tab. 2 Output data of the Simulation Model.

\begin{tabular}{|c|l|c|}
\hline Subsystem & \multicolumn{1}{|c|}{ Parameter name } & Sign \\
\hline \multirow{3}{*}{$(\mathbf{P})$} & Process duration & $\mathrm{T}_{\mathrm{ICP}}$ \\
\cline { 2 - 3 } & Number of cycles & $\mathrm{m}$ \\
\hline \multirow{3}{*}{$(\mathbf{C}) \mathbf{w}$} & Processing performance of FC & $\mathrm{P}_{(\mathrm{C})}$ \\
\cline { 2 - 3 } & Average length of queue & $\mathrm{DFp}$ \\
\cline { 2 - 3 } & Maximum length of queue & $\mathrm{DFm}$ \\
\cline { 2 - 3 } & Average waiting time in queue & $\mathrm{TFp}$ \\
\cline { 2 - 3 } & Maximum waiting time in queue & $\mathrm{TFm}$ \\
\hline
\end{tabular}

\section{THE RESULTS OF THE SIMULATION EXPERIMENTS}

Based on the data obtained from the actual observed and analyzed integrated construction processes, the so- called "basic" process has been set Its parameters are:

Processing performance of FC $\quad \mathrm{P}_{(\mathrm{S})} \quad: \quad 30 \quad \mathrm{~m}^{3} / \mathrm{h}$

Process size (volume) $\quad \mathrm{Q}_{\mathrm{ICP}} \quad: \quad 250 \mathrm{~m}^{3}$

Number of trucks $\quad \mathrm{PV}: 5 \quad$ -

Average transportation capacity $\mathrm{O}_{\mathrm{pr}} \quad: \quad 7,5 \quad \mathrm{~m}^{3} /$ cycle

Dosage performance of FC $\quad \mathrm{P}_{(\mathrm{P})} \quad: \quad 50 \quad \mathrm{~m}^{3} / \mathrm{h}$ 


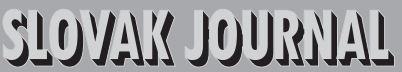 \\ 1) 5

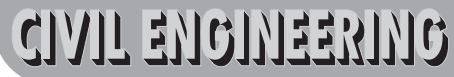

Vol. XXI, 2013, No. 2, 1 - 6

Experiments were made with the created simulation model in order to identify the effects of the crucial variables, total performance, duration and discipline in the subsystem (C). The input parameters for generating random delays (triangular distribution) were defined as follows (Tab 4).

Tab. 3 The input parameters for generating random delays in the experiments.

\begin{tabular}{|l|c|c|c|}
\hline Activity & MIN & OPT & MAX \\
\hline Duration of manipulation in (P), [min] & 3 & 4 & 5 \\
\hline Transport duration from (P) to (C), [min] & 8 & 12 & 14 \\
\hline Transport duration from (C) to (P), [min] & 7 & 9 & 12 \\
\hline Duration of manipulation in (P), [min] & 3 & 4 & 5 \\
\hline
\end{tabular}

By alternating the average transportation capacity, a reduction of the duration of the process of only about $14 \%$ was attained (Fig. 4). From the point of view of the number of cycles, it is a reduction of about $30 \%$, but in terms of negative traffic conditions, it may be crucial.

In a given range of processing performance, a shortening of the process's duration is achieved, while there is a significant decrease in the average waiting time in the queue (Figs. 5,6). In the event of changes in the processing, the performance is confirmed by the great impact of this parameter on the duration of the process as well as in subsystem (C) is discipline.

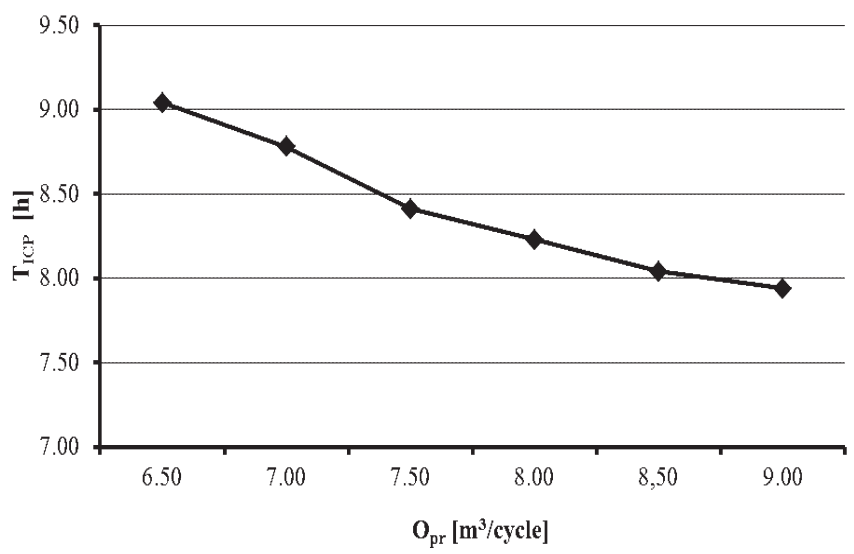

Fig. 4 Simulation output - Duration of process for various average transportation capacities.

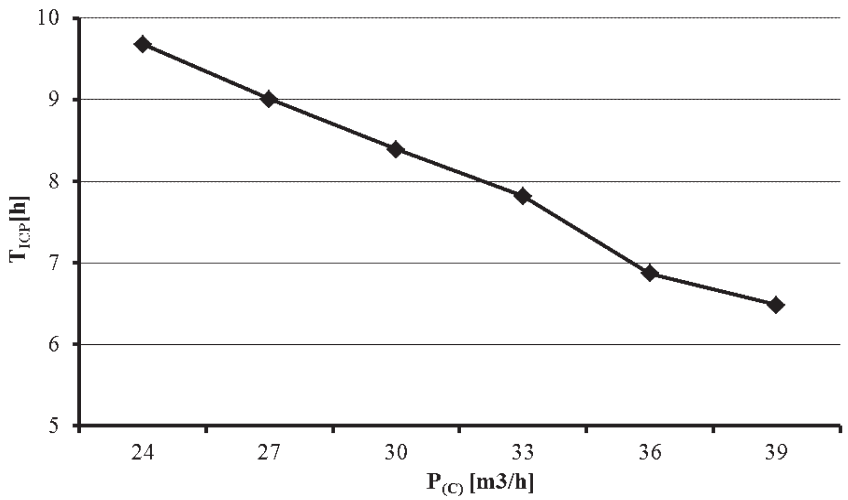

Fig. 5 Simulation output -Duration of process for various processing performances.

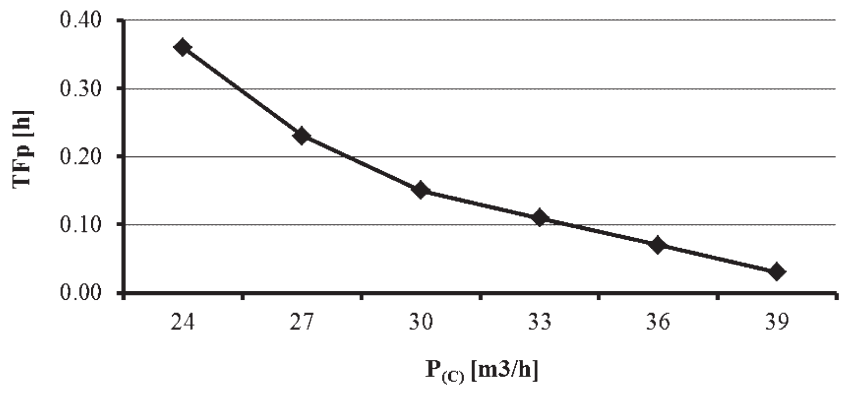

Fig. 6 Simulation output - Average waiting time in a queue for various processing performances.

As we can see in Fig. 7, the selected number of trucks sensitively react to the truck's waiting time in the queue, while the duration of the process from $\mathrm{PV}=6$ has a slightly decreasing character (Fig. 8).

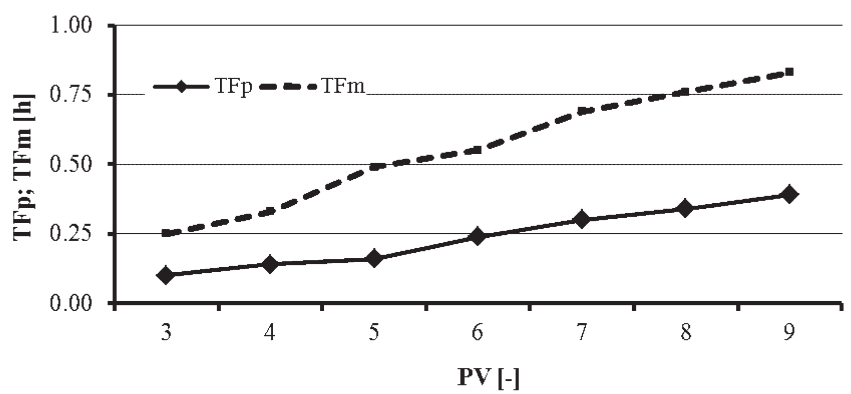

Fig. 7 Simulation output - Waiting time in a queue for various number of trucks. 


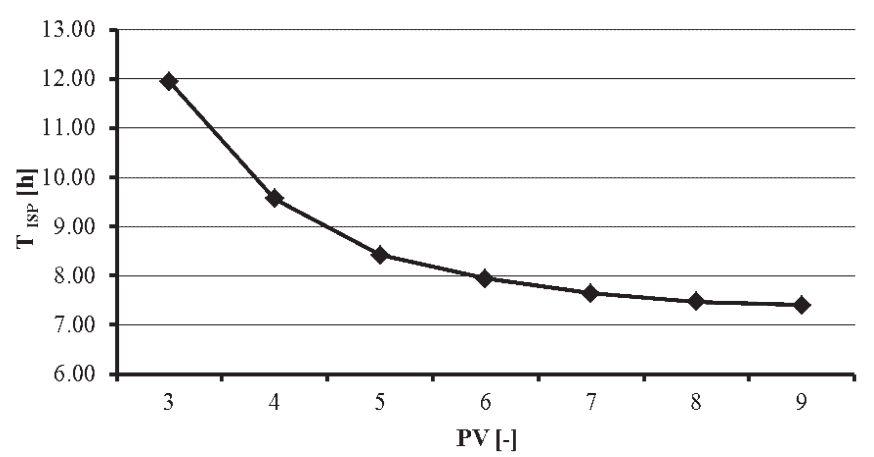

Fig. 8 Simulation output - Duration of process for a various number of trucks.

The graphic results of the experiments made by changing one input parameter indicates that a major reduction in the process with a minimum amount of idleness can be achieved by combining two parameters simultaneously. It is mainly a combination of the average transportation capacity $\mathrm{O}_{\mathrm{pr}}$ and processing performance $\mathrm{P}_{(\mathrm{C})}$.

Based on this knowledge base the basic process after a change in these two parameters is defined as the "optimized basic process," and its characteristics are shown in Tab. 5.

Tab. 4 Comparison of the base process and optimized base process.

\begin{tabular}{|l|c|c|}
\hline Parameter & $\begin{array}{c}\text { Basic } \\
\text { process }\end{array}$ & $\begin{array}{c}\text { Optimized } \\
\text { basic } \\
\text { process }\end{array}$ \\
\hline Number of trucks PV [-] & 5 & 5 \\
\hline Average transportation capacity $\mathrm{O}_{\mathrm{pr}}\left[\mathrm{m}^{3} /\right.$ cycle $]$ & 7,5 & 8,5 \\
\hline Processing performance $\mathrm{P}_{(\mathrm{C})}\left[\mathrm{m}^{3} / \mathrm{h}\right]$ & 30 & 40 \\
\hline Total duration of the process $\mathrm{T}_{\mathrm{ICP}}[\mathrm{h}]$ & $\mathbf{8 , 4 0}$ & $\mathbf{5 , 9}$ \\
\hline Average length of queue $\mathrm{DFp}[-]$ & $\mathbf{0 , 9 7}$ & $\mathbf{0 , 2 7}$ \\
\hline Average waiting time in queue $\mathrm{TFp}[\mathrm{h}]$ & $\mathbf{0 , 1 5}$ & $\mathbf{0 , 0 4}$ \\
\hline
\end{tabular}

An important fact, which is essential for the adoption of optimizing interventions in "concreting" processes, is the discipline on the site the average and maximum waiting time of trucks in a queue because of the limited processing time of fresh concrete.

The processed outputs of the simulation experiments made with the simulation model provide a range of data indicating a functional dependence between the number and average capacity of the concrete mixers, processing performance and the overall duration of the process.

\section{CONCLUSION}

This paper has presented the design and construction of an integrated construction process, i.e., the production-transport-usage of fresh concrete. By creating a model in Extend v4, modelling techniques and a general knowledge of construction were used. The model parameters and input variables used data obtained from real processes. It should be noted that in the interest of the accuracy of the results, it is necessary to carefully analyze the on-site processes because of the uniqueness of each building.

Based on the analysis of real processes, a so called "basic process" was designed, which has subsequently been found by simulating the parameter values. The very structure of the model makes it easy to build alternatives (scenarios) and subsequently testing them.

The main contribution of the paper is the development of a simulation model of the process for the optimization and selection of the variants. This approach complements the heuristic methods of the assessment of construction processes and exact methods, where the decisive body should have the values of the individual decision-making criteria. The advantage of this approach in technical works is that it is possible to visualize the future behaviours of the system, and based on this knowledge, to make the necessary interventions in a real system.

The simulation results achieved showed that only the rational design of the processing performance of fresh concrete with the correct number of trucks can be achieved by reducing the total value of the process. 


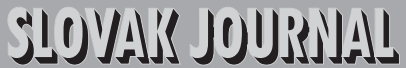 \\ 1)

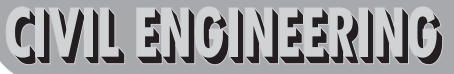

Vol. XXI, 2013, No. 2, 1 - 6

\section{REFERENCES}

Smith, S.D. (1998) Concrete placing analysis using discrete-event simulation. Proceedings of the Institute of Civil Engineers, Structures and Buildings, 128(4), 351-358.

Smith, S.D. (1999) Modelling and experimentation of the concrete supply and delivery process. Civil Engineering and Environmental Systems, 16, 93-114.
Dunlop P. and Smith S. (2003) Estimating key characteristics of the concrete delivery and placement process using linear regression analysis. Civil Engineering and Environmental Systems, 20(4), 273-290.

Straka, M. (2007) Discrete-event and continuous simulation in Extend simulation language, University of Technology Košice, ISBN 978-80-8073-884-6. 